\title{
MODEL BISNIS PERUSAHAAN JAMUR SKALA BESAR DI NEGARA JEPANG (Studi Kasus Yukiguni Maitake Co., Ltd., Niigata, Jepang)
}

\author{
FEBY CLAUDYA NAVELDA*, GEMA WIBAWA MUKTI \\ Program Studi Agribisnis, Fakultas Pertanian, Universitas Padjadjaran \\ *Email: fcnavelda@gmail.com
}

\begin{abstract}
ABSTRAK
Yukiguni Maitake Co., Ltd. merupakan perusahaan agribisnis yang berada di Niigata, Jepang. Basis bisnis perusahaan berupa produksi dan penjualan jamur maitake, bunashimeji, eringgi, makanan sehat dan olahan. Perusahaan ini merupakan perusahaan terbesar kedua di Jepang yang telah berdiri selama 35 tahun. Mampu membangun karir bisnis membuat Yukiguni Maitake Co., Ltd. dapat dijadikan inspirasi bagi pelaku bisnis. Fokus penelitian ini ialah menggambarkan model bisnis Yukiguni Maitake Co., Ltd. Penelitian ini merupakan penelitian kualitatif dengan teknik studi kasus. Peneliti menggunakan alat analisis Business Model Canvas dengan pendekatan Design Thinking. Dari hasi penelitian, customer segments perusahaan ialah pasar tersegmentasi. Value propositions yang diberikan ialah produk aman dan terpercaya, diferensiasi produk yang beragam. Channels perusahaan berupa direct dan indirect selling. Customer relationships yang dilakukan berupa personal assitance. Revenue streams didapat dari penjualan produk. Key resources terdiri atas aset fisik, karyawan, modal milik pribadi, dan sumber intelektual yaitu sertifikat ISO 22000, brand yukiguni maitake. Key activities berupa budidaya, pengemasan, dan distribusi. Adapun key partnership terbagi dua, yaitu suppliers dan buyers. Terakhir, cost structure terdiri atas biaya bahan baku, tenaga kerja, dan operasional.
\end{abstract}

Kata kunci: Yukiguni Maitake Co., Ltd., Model Bisnis, Design Thinking

\begin{abstract}
Yukiguni Maitake Co., Ltd. is an agribusiness company that is located in Niigata, Japan. Business line of this company are production and sales of maitake, bunashimeji, king oyster mushrooms, healthy and processed food. The company is the second largest mushroom company that has been established for 35 years. The company is able to build a career and it can be an inspiration for agriculture actors. The focus of this research is description of Yukiguni Maitake Co., Ltd. 's business model. The research design is a qualitative method with case study technique. The research used frameworks of Business Model Canvas with Design Thinking approach. The results of this research indicated that customer segments is segmented market. Value propositions are safety and trusted food, various kind of products. The company used direct and indirect selling as a channel. Customer relationship used is personal assistance. Revenue streams were obtained from sales of its products. Key resources consist of physical assets, human resources, personal capital and for intelectual resources are ISO 22000 and yukiguni's brand. Key activities included are cultivation, packaging, and distribution activity. Key partnerships are suppliers and buyers. The last one is cost structure which consists of raw materials, labor, and operation costs.
\end{abstract}

Keywords: Yukiguni Maitake Co., Ltd, Business Model, Design Thinking 


\section{PENDAHULUAN}

Hortikultura merupakan salah satu subsektor dalam pertanian yang memberikan kontribusi bagi manusia dan lingkungan. Pengaruh gaya hidup sehat membuat hortikultura yaitu tanaman buahbuahan dan sayur-sayuran diminati masyarakat. Euromonitor International ${ }^{1}$ menyatakan bahwa di bagian Asia Pasifik, masyarakat mengkonsumsi sayur dan buah rata-rata 560 gram per kapita per hari, melebihi rekomendasi yang diberikan $\mathrm{WHO}^{2}$ yaitu minimal 400 gram sayur dan buah per hari. Di Asia Pasifik, sayuran merupakan makanan sehat yang menonjol sebesar $42 \%, 22 \%$ berupa buah, dan $36 \%$ sisanya merupakan umbi-umbian, ikan, daging, dan sebagainya (Euromonitor International, 2015).

Salah satu komoditas sayuran yang banyak dikonsumsi ialah jamur. Dalam sejarahnya jamur telah dikenal sebagai makanan sejak 3.000 tahun silam, dimana jamur telah menjadi hidangan masyarakat dinasti Cho. Salah satu negara yang mengonsumsi jamur adalah Jepang. Beberapa jenis jamur yang populer di pasaran Jepang ialah enokitake, maitake, matsutake, shiitake, shimeji, jamur kuping (Haiwei Sun, 2010). Jamur dianggap

\footnotetext{
1 Euromonitor International adalah Badan yang melakukan riset pasar tentang produk konsumen, industri komersial, tren demografi, dan gaya hidup konsumen di dunia.
}

sebagai unsur penting dalam makanan Jepang dan memiliki pengaruh pada budaya Jepang. Makanan di Jepang dipengaruhi oleh dua konsep. Konsep pertama ialah makanan dikategorikan sebagai pokok dan kedua sebagai karunia alam. Konsep pertama menjelaskan makanan pokok terdiri dari nasi, miso, dan ikan. Sedangkan konsep kedua makanan berdasarkan karunia alam ialah makanan dari hasil hutan. Hasil hutan kategori sayuran liar "wild food" memiliki tempat penting dalam masakan Jepang. Jamur merupakan tanaman kategori "wild food" utama yang dicari oleh petani Jepang. Dari 180 jamur yang dapat dikonsumsi terdapat 10 yang sudah dibudidayakan secara komersial dan beberapa diantaranya sudah dikenal diluar Jepang (Ashkenazi \& Jacob, 2003).

Jepang merupakan negara 4 musim yang memiliki budaya makanan cukup unik. Sepanjang cuaca dingin, masyarakat Jepang memiliki kebiasaan mengonsumsi sup hangat. Terdapat 3 metode memasak sup yang terkenal yaitu nabemono (satu panci panas), shirumono (sup dan kaldu yang direbus), dan suimono (sup bening). Sup Jepang biasanya terdiri atas berbagai jenis sayuran dan jamur segar (Ashkenazi \& Jacob, 2003). Menurut Yamanaka

\footnotetext{
${ }^{2}$ WHO singkatan dari World Health Organization
} 
(2011), produksi jamur terjadi di semua musim. Namun, harga eceran akan tinggi dari September hingga Februari dan akan lebih rendah dari Maret hingga Agustus karena orang Jepang cenderung mengonsumsi banyak jamur selama musim gugur dan musim dingin terutama digunakan untuk nabemono (hot-pot cooking).

Jamur sudah menjadi salah satu hidangan penting dalam masakan Jepang. Hal ini berpengaruh pada kemampuan produsen untuk produksi jamur dan memenuhi permintaan konsumsi. Berdasarkan data statistik masyarakat Jepang mengkonsumsi 3,4 kg jamur per orang per tahun (Dyck dan ito 2001 dalam Haiwei 2010). Bila dikaitkan dengan jumlah penduduk Jepang yaitu 127 juta jiwa maka produksi dalam negeri belum dapat terpenuhi. Hal ini didukung dengan data dari Global Trade Altas (2015) dimana Jepang berada di peringkat ke-3 sebagai negara pengimpor berdasarkan value kategori jamur segar. Jepang juga berada di peringkat ke-3 sebagai negara pengimpor berdasarkan value kategori jamur dried (Trademap, 2015).

Fenomena ini menunjukan bahwa Jepang merupakan negara dengan konsumsi jamur tinggi tetapi produksi

${ }^{3}$ Salah satu koran di jepang. Judul artikel "Top Japanese mushroom companies look to other Asian dalam negeri masih belum dapat terpenuhi. Hal positif yang dapat dilihat bahwa pelaku-pelaku agribisnis komoditas jamur terus mengalami perkembangan dan memberikan peluang untuk meningkatkan produksi. Salah satunya adalah Yukiguni Maitake Co. Ltd. Menurut The Mainichi Japan's National Daily ${ }^{3}$ (2016), Yukiguni Maitake Co. Ltd. adalah salah satu dari dua perusahaan besar yang berkecimpung dalam komoditas jamur. Perusahaan yang berdiri tahun 1983 ini memproduksi jamur bunashimeji, maitake, eringgi, cut vegetables, dan makanan olahan jamur. Produk yang diunggulkan perusahaan ialah jamur maitake. Berdasarkan survei perusahaan lebih dari 50\% jamur maitake yang tersebar di Jepang berasal dari Yukiguni Maitake Co., Ltd. Hal ini menjadikan Yukiguni Maitake Co., Ltd. sebagai perusahaan terbesar di Jepang yang memproduksi jamur maitake dan merupakan perusahaan terbesar kedua di Jepang yang memproduksi bunashimeji (Yamakana, 2011). Selain Yukiguni Maitake Co., Ltd. terdapat beberapa perusahaan jamur dalam negeri dan luar negeri juga yang mengimpor ke Jepang sehingga berpengaruh pada ketatnya persaingan pasar.

markets" 18 september 2016 (diakses 3 agustus 2017) 
Fenomena pasar dan ketatnya persaingan dalam dan luar negeri menjadi tantangan bagi Yukiguni Maitake Co., Ltd. Perusahaan harus mampu memenuhi permintaan dan bersaing dengan pesaingpesaing baru yang juga mengincar konsumen di Jepang. Inovasi strategi bisnis perlu dilakukan oleh perusahaan setiap saat, agar dapat bertahan dalam dunia bisnis. Strategi bisnis dapat dibentuk melalui bantuan model bisnis. Model bisnis dapat menyederhanakan realita bisnis yang kompleks menjadi elemen-elemen yang mudah dipahami. Yukiguni Maitake Co., Ltd. sudah berdiri 35 tahun dan sukses menjadi salah satu perusahaan jamur terbesar di Jepang. Menyadari kondisi perusahaan akan membantu Yukiguni Maitake Co., Ltd. membuat rencanarencana yang menghasilkan value propositions bagi perusahaan.

Dengan beberapa uraian yang telah disampaikan di atas. Penelitian ini bertujuan untuk mengetahui dan memahami model bisnis yang diterapkan oleh Yukiguni Maitake Co., Ltd. Salah satu caranya dengan menggunakan pendekatan Business Model Canvas (BMC). Pendekatan yang dikembangkan oleh Osterwalder dan Yves Pigneus dipilih karena dapat disajikan dalam bentuk visual berupa suatu kanvas lukisan dan mudah dimengerti oleh pembaca. Sehingga nantinya diharapkan hasil pemetaan model bisnis ini dapat menjadi benchmark bagi pelaku-pelaku bisnis sejenisnya.

\section{METODE PENELITIAN}

Penelitian berlangsung di Yukiguni Maitake Co., Ltd., Niigata, Jepang. Objek penelitian ialah model bisnis yang diterapkan perusahaan. Rancangan penelitian yang digunakan ialah desain kualitatif dengan teknik studi kasus. Peneliti menggunakan alat analisis Business Model Canvas (BMC). Business Model Canvas bertujuan untuk memetakan proses bisnis suatu perusahaan dimana didalamnya terdapat 9 aspek yang dijadikan operasional variabel yang terdiri atas Customer Segments, Value Propositions, Channels, Customer Relations, Revenue Streams, Key Resources, Key Activities, Key Partnerships, Cost Structure.

Peneliti memilih informan yang dianggap paling mengetahui masalah yang dikaji. Narasumber yang menjadi informan pada penelitian ini terdiri atas kepala kantor, pewakilan HRD, manager produksi, distribusi, serta beberapa karyawan tetap.

Sumber data diperoleh dari observasi, wawancara, dan studi literatur yang menggunakan pendekatan design thinking sebagai cara peneliti memperoleh, menerima, dan mengolah data. Data dituangkan dalam bentuk narasi dan didukung oleh dokumentasi berupa gambar, tabel, dan diagram alur. Penarikan 
kesimpulan dilakukan dengan mengambil poin kunci dari setiap variabel yang diteliti dan direalisasikan dalam bentuk prototipe Business Model Canvas.

\section{HASIL DAN PEMBAHASAN}

\section{Profil Yukiguni Maitake Co., Ltd.}

Yukiguni Maitake. Co., Ltd. merupakan perusahaan besar agroindustri komoditas jamur yang berdiri tahun 1983 dan berlokasi di 89, Yokawa, Minamiuonuma-shi. Niigata, Jepang. Perusahaan ini mengusahakan beberapa jenis jamur, yaitu jamur maitake, jamur maitake putih, jamur eringgi, dan jamur bunashimeji. Selain memproduksi jamur, Yukiguni Maitake Co., Ltd. juga mengolah jamur dengan mendiferensiasikan produknya menjadi produk makanan sehat dan makanan olahan. Adapun produk makanan sehat yaitu jus hijau (green juice), kapsul Maitake, MD-fraction 100, dan sayuran potong. Sedangkan makanan olahan (processed food) yang dikeluarkan ialah kari jamur, kaldu jamur, maitake rebus, forzen maitake, dan natto.

Yukiguni Maitake Co., Ltd. merupakan leading company dalam produksi dan budidaya jamur, khususnya jamur maitake. Perusahaan ini memiliki kantor pemasaran yang tersebar di tujuh kota besar di Jepang, yaitu Niigata, Tokyo, Nagoya, Osaka, Sendai, Hokkaido, dan Hiroshima. Perusahaan ini juga memiliki sertifikat aman pangan ISO 22000 dan telah memiliki sistem tracebility serta berhasil megembangkan jamur yang aman dan bebas pestisida.

\section{Analisis Model Bisnis Kanvas}

\section{Customer Segments}

Pelanggan merupakan kunci penting dari berjalannya perusahaan. Perusahaan perlu menentukan segmentasi pasar agar dapat memenuhi kebutuhan pelanggan. Yukiguni Maitake Co., Ltd. memiliki customers segments dengan jenis pasar tersementasi (segmented market) dimana perusahaan mengelompokkan pelanggan dalam berbagai segmen yang memiliki kebutuhan maupun masalah yang disesuaikan dengan segmen pasarnya.

Yukiguni Maitake Co., Ltd. mensegmentasikan pasarnya berdasarkan demografi yaitu berusia 20 hingga 60 tahun. Pendekatan psikografi meliputi gaya hidup sehat masyarakat Jepang dan budaya masakan Jepang yaitu menghidangkan sup (nabemono) dimana salah satu bahan utamanya ialah jamur. Pendekatan geografi ialah Jepang mengalami empat musim dan didominasi cuaca dingin dari bulan Oktober - Maret. Berdasarkan hasil wawancara, dijelaskan bahwa permintaan akan jamur maitake cenderung tinggi pada bulan Oktober sekitar 900.000 kilogram dan terendah pada bulan Juli 500.000 kilogram 
Dapat dilihat bahwa terjadi kenaikan permintaan 1,5 hingga 2 kali lipat jamur bila memasuki musim dingin.

\section{Value Proposition}

Value proposition ialah nilai yang ada dalam suatu produk sehingga produk tersebut berbeda dari jenis lainnya. Adapun Value proposition yang diberikan dari Yukiguni Maitake Co., Ltd. kepada konsumen adalah 1) Kinerja. Yukiguni Maitake Co., Ltd. selalu berusaha menghasilkan produk yang berkualitas. Perusahaan melakukan kontrol terhadap tiap aspek baik itu kebersihan bahan baku, mesin, hingga pekerja. Perusahaan melakukan inspeksi untuk memeriksa bahan radioaktif di jamur dan sayuran potong yang mereka buat. Perusahaan juga memantau kondisi kebersihan air, peralatan, dan bahan lainnya yang digunakan dalam budidaya. Pekerja juga memiliki pakaian khusus yang menutupi seluruh tubuh. Hal ini dilakukan untuk menghindari jamur terkontaminasi dari kotoran. 2) Kustomisasi, Yukiguni Maitake Co., Ltd. memberikan kesempatan kepada konsumen untuk memesan produk sesuai keinginan. Konsumen dapat menentukan ukuran, kemasan, serta kardus kemasan sesuai keinginan. 3) Penyelesaian Pekerjaan. Yukiguni Maitake Co., Ltd. memiliki diferensiasi produk yang disesuaikan dengan kebutuhan konsumen.
Salah satunya ialah makanan olahan. Makanan olahan dapat disiapkan dengan cepat yang mana sangat membantu menyelesaikan pekerjaan ibu rumah tangga. Perusahaan menjual beberapa jenis makanan seperti nasi instan, kaldu, dan kari jamur yang sering menjadi menu utama di meja makan orang Jepang. 4) Design dan Merek. Konsumen di Jepang sangat memperdulikan tampilan dari suatu produk. Perusahaan mengetahui apa yang diinginkan konsumen sehingga mereka merepresentasikan produk-produknya sebagai berikut: jamur maitake di kemas dengan bentuk menyerupai kipas, jamur bunashimeji dikemas sebanyak dua bonggol dengan ukuran 100 gram, jamur eringgi (king osyter) dikemas sebanyak dua hingga tiga buah dalam kemasan 100 gram. Sedangkan kekuatan brand/merek perusahaan didapat dari kepopuleran jamur andalan yaitu jamur maitake. Yoshinobu Ordaira ialah petani sekaligus pendiri perusahaan dimana beliau menjadi orang pertama yang dapat membudidayakan jamur maitake di Jepang. Sehingga Yukiguni Maitake Co., Ltd. berhasil menjadi leading company untuk kategori jamur maitake dan menjadi perusahaan kedua terbesar di Jepang. 5) Pengurangan Risiko. Yukiguni Maitake Co., Ltd. menghadirkan sistem tracebility pada produknya. Tracebilty ialah kemampuan untuk melacak asal mula produk. Yukiguni 
Maitake Co., Ltd. telah menerapkan tracebility terhadap produk-produk jamurnya melalui $Q R$ code di kemasan. Konsumen dapat mengetahui spesifikasi produk dari $Q R$ code yang dapat dilacak di link www.yukiguni-anzen.jp. $Q R$ code ini tidak diterapkan oleh semua perusahaan jamur sehingga produk Yukiguni Maitake Co., Ltd. memiliki kelebihan dibandingkan produk jamur lainnya. 6) kemudahan Pengguna. Yukiguni Maitake Co., Ltd. menawarkan produk dengan berbagai ukuran dan jenis. Konsumen diberikan kebebasan untuk memilih ukuran dan jenis jamur. Standar ukuran yang ditawarkan perusahaan ialah 50 gram, 80 gram, 100gram, 130 gram, 150 gram, 200 gram, 350 gram, 500gram, dan 800 gram (ukuran 1 buah maitake). Selain ukuran terdapat diferensiasi berdasarkan jenis produk yaitu kinoko seto ialah jenis produk yang mengombinasikan tiga jenis jamur dalam satu kemasan dan jenis kasa ialah kemasan yang hanya berisi daun jamur.

\section{Channel}

Channel adalah saluran yang menghubungkan Yukiguni Maitake Co., Ltd. dengan konsumen. Yukiguni Maitake Co., Ltd. memiliki dua cara. Pertama, indirect selling yaitu kegiatan penyaluran produk dengan mendistribusikan dalam jumlah besar ke mitra (retailer). Seluruh kegiatan jual beli hanya dapat dilakukan oleh retailer. Retailer yang bekerja sama dengan Yukiguni Maitake Co., Ltd. ialah supermarket besar yang tersebar diseluruh wilayah Jepang yang terdiri dengan nama Rara, Aeon, Izumi, Yaoko, Harashin, Ozeki, Raifukoporeshon, dan Heiwado.

Kedua, direct selling, yaitu kegiatan penyaluran produk secara langsung kepada konsumen. Bentuk direct selling yaitu konsumen dapat datang ke restoran Yukiguni Maitake yang terletak 200 meter dari kantor pusat. Restoran tersebut menjual menu makanan berbahan dasar jamur dan souvenir makanan yang memiliki waktu kadaluarsan yang cukup lama seperti kari jamur, kaldu jamur, dan kapsul kesehatan berbahan dasar jamur yang dikenal dengan nama MD-Fraction.

\section{Customer Relationship}

Customer Relationship ialah hubungan yang dibangun antara perusahaan dengan pelanggan (customer). Perusahaan melakukan cara personal assitance yaitu pola hubungan yang didapatkan dari interaksi antar individu. Perusahaan memiliki wakil perusahaan untuk membantu selama proses pembelian dan pasca pembelian. Bentuk nyata yang diterapkan ialah melalui call center dan email. Pelanggan dapat menghubungi call center atau meng-email untuk kegiatan pemesanan maupun pengeluhan produk. 
Mitra merupakan bagian penting dalam perusahaan. Yukiguni Maitake Co., Ltd. memiliki cara untuk tetap dapat menjalin dan mempertahankan hubungan yang baik dengan mitranya, hal yang dilakukan ialah mengikuti aturan yang ada di kontrak, meng-update harga, dan selalu menjalin komunikasi.

\section{Revenue Stream}

Revenue stream adalah pendapatan yang diperoleh perusahaan yang biasanya diukur dalam bentuk uang. Yukiguni Maitake Co., Ltd. memperoleh pendapatan yaitu dari penjualan (sale) produk itu sendiri.

\section{Key Resources}

Key resources adalah segala sumber daya yang dimiliki suatu perusahaan untuk menjalankan kegiatan bisnisnya. Adapun key resources yang dimiliki perusahaan adalah 1) Sumber daya fisik yang terdiri atas Kantor Pusat, Kantor Pemasaran (Sales Office), Depo atau gudang penampung produk-produk, laboratorium penelitian, mesin, truk berpendingin, pabrik atau bioteknologi.

Terdapat 6 bioteknologi dengan spesifikasi yaitu bioteknologi 1 (dai-ichi), bioteknologi 3 (dai-san), dan Gozen bioteknologi merupakan tempat budidaya dan produksi jamur maitake, bioteknologi 4 (dai-yon) sebagai tempat budidaya hingga pengemasan jamur eringgi, dan bioteknologi 5 (dai-go) merupakan tempat budidaya hingga pengemasan jamur bunashimeji, dan bioteknologi 2 (dai-ni) tempat pembuatan media tanam (ongaku).

Tabel 1. produksi di Yukiguni Maitake Co., Ltd.

\begin{tabular}{lll}
\hline \multicolumn{1}{c}{ Jenis } & \multicolumn{1}{c}{ Keterangan } & \multicolumn{1}{c}{$\begin{array}{c}\text { Kuantitas } \\
\text { Produksi }\end{array}$} \\
\hline Bioteknologi 1 & Jamur maitake & \pm 33 ton / hari \\
Bioteknologi 2 & Media tanam & \pm 33 ton / hari \\
Bioteknologi 3 & Jamur maitake & \pm 33 ton / hari \\
Bioteknologi 4 & Jamur eringgi & \pm 29 ton / hari \\
Bioteknologi 5 & Jamur bunashimeji & \pm 39 ton / hari \\
Bioteknologi & Jamur maitake & \pm 33 ton / hari \\
Gosen & & \\
\hline Sumber : Yukiguni Maitake Co., Ltd., 2017
\end{tabular}

Sumber : Yukiguni Maitake Co., Ltd., 2017

2) Sumber daya manusia (human). Terbagi menjadi dua bagian besar yaitu: Karyawan kantor dan Karyawan pabrik.

Tabel 2. Jumlah Tenaga Kerja Yukiguni Maitake Co., Ltd.

\begin{tabular}{ll}
\hline \multicolumn{1}{c}{ Jenis } & Jumlah Karyawan \\
\hline Bioteknologi 1 & \pm 270 orang \\
Bioteknologi 2 & \pm 30 orang \\
Bioteknologi 3 & \pm 200 orang \\
Bioteknologi 4 & \pm 230 orang \\
Bioteknologi 5 & \pm 330 orang \\
Bioteknologi Gosen & \pm 370 orang \\
Kantor Pusat dan Pusat & \pm 260 orang \\
Pengemasan & \\
Pusat Pengemasan Shiga & \pm 60 orang \\
Sumber : Yukiguni Maitake Co., Ltd., 2017
\end{tabular}

3) Sumber daya intelektual berupa brand Yukiguni Maitake dan sertifikasi ISO 22000 yaitu sertifikat yang dikeluarkan oleh badan internasional yang menandakan bahwa suatu organisasi telah memiliki standar keamanan pangan diseluruh rantai pasok produknya dari mulai produsen, pengolahan, pengepakan, hingga transportasi dan penjualan. 4) Sumber daya finansial berupa modal awal perusahaan 
ialah modal pribadi sebesar 100.000 .000 yen.

\section{Key Activities}

Terdapat tiga aktivitas yang dilakukan perusahaan meliputi; produksi, distribusi, dan pemasaran. Aktivitas produksi yang dilakukan di Perusahaan terbagi menjadi dua yaitu aktivitas on farm dan off farm. Berikut merupakan penjelasan kegiatan budidaya (on farm) yang dilakukan perusahaan:

a. Inspeksi bahan baku. Bahan baku terlebih dahulu diteliti oleh tim reseachers. Terdapat empat tahapan uji terhadap bahan baku yaitu uji bahan radioaktif, uji bahan kimia, uji logam berat, dan uji higienis.

b. Pembuatan kultur medium dan sterilisasi media tanam. Proses pembuatan ialah kegiatan pencampuran dan pengadukan serbuk kayu berdaun lebar, dedak gandum dan air. Setelah tercampur, bahan baku dimasukan kedalam plastik (baglog) yang telah diberikan lubang untuk tumbuh jamur. Kegiatan ini dilakukan oleh mesin. Berat 1 baglog yaitu 2800 gram. Setelah itu, baglog akan di strerilisasi. Strerilisasi ialah proses pemanasan baglog dengan suhu $110-120{ }^{\circ} \mathrm{C}$ guna membasmi bakteri saprofit yang terdapat dalam media tanam. c. Inkubasi. Inkubasi merupakan proses pemberian bakteri maitake ke dalam baglog. Bakteri maitake memiliki berat 3 gram. Setelah inkubasi, baglog akan dibawa ke ruang perkecambahan.

d. Perkecambahan. Baglog akan disusun di rak bertingkat dalam suatu ruangan. Ruangan ini disebut ruang musim panas karena jamur maitake mulanya dapat tumbuh baik di suhu musim panas. Jamur didiamkan dalam ruang perkecambahan ini selama 70 hari. Dan suhu rata-rata ruangan ialah $23-26^{\circ} \mathrm{C}$.

e. Pembiakan. Pada masa pembiakan jamur akan dipindahkan keruangan musim gugur. Pada ruangan ini diatur cahaya, tata letak baglog, temperatur, dan kelembaban seperti musim gugur di dalam hutan. Pembiakan ini dilakukan selama delapan hingga sepuluh hari hingga akhirnya memasuki proses panen.

f. Panen. Kegiatan panen dilakukan dengan memotong langsung jamur maitake menggunakan tangan dan diletakan dalam keranjang container. Jamur maitake yang diproduksi perusahaan memiliki berat \pm 800 gram hingga 1 kilogram.

Aktivitas produksi selanjutnya dilakukan di head office (Honsha packaging center). Adapun kegiatan off farm yang dilakukan ialah distribusi jamur, 
pengepakan, distribusi ke ruang penyimpanan, distribusi ke sales office.

a. Distribusi Jamur. Kegiatan pendistribusikan jamur ke kantor pusat dengan truk berpendingin. Dalam satu hari, pendistribusian dapat dilakukan sebanyak lima hingga enam kali. Setiap jamur nantinya memiliki kertas barcode penunjuk kapan jamur itu dipanen, jam berapa, tanggal, berat keseluruhan.

b. Pengemasan jamur Maitake dan Packaging. Merupakan kegiatan pengemasan jamur dengan spesifikasi khusus yang sudah ditetapkan oleh perusahaan. Terdapat beberapa pengecekan yang terjadi yaitu mesin Xray, mesin timbangan, mesin sticker.

c. Distribusi ke ruang penyimpanan dan distribusi ke kantor penjualan seJepang. Setelah pengemasan. Jamur akan di simpan dalam cold storage. Jamur selanjutnya didistribusikan ke depo (gudang penyimpanan) yang berada di kantor pemasaran.

Kegiatan pemasaran ialah cara perusahaan memasarkan produknya. Terdapat tiga kegiatan utama yang dilakukan meliputi; 1) Publikasi melalui Media sosial. Yukiguni Maitake Co., Ltd. menggunakan website yaitu maitake.co.jp, facebook, dan twitter untuk memasarkan produk-produknya. Web browser tersebut memberikan informasi berupa profil perusahaan, sertifikat dan jaminan produk, jenis produk, metode pemesanan, serta menawarkan resep mengolah jamur, bahkan di website perusahaan juga menyediakan informasi lowongan kerja yang sedang dibuka. 2) Testimoni dan demo masak. Bentuk pemasaran berupa memasak jamur menjadi hidangan dan memberikan testimoni kepada konsumen. Kegiatan ini rutin dilakukan di pasar grosir buah dan sayuran Tokyo. 3) Kolaborasi brand. Bentuk kolabosi brand yang dilakukan ialah mengajak perusahaan Ajinomoto Co., Inc untuk membuat resepresep dengan bahan utama jamur. Yukiguni Maitake Co., Ltd. juga pernah berkolaborasi dengan perusahaan mie Jepang (ramen) yaitu Toyo Suisan Kaisha, Ltd.

\section{Key Partnership.}

Key partnership adalah mitra utama yang membantu perusahaan dalam menjalankan model bisnisnya. Mitra utama biasanya berupa supplier kegiatan produksi dari hulu hingga ke hilir. Adapun mitra utama perusahaan Yukiguni Maitake Co., Ltd. ialah Omori Machinery Co., Ltd, Fujimori Kogyu Co., Ltd, Settsucarton Co., Ltd, Midori Anzen Co., Ltd, Chuo Kagaku. Co., Ltd, Sagawa Express Co., Ltd, Yamato Transport Co., Ltd.

\section{Cost structure}

Cost Structure ialah biaya yang dikeluarkan perusahaan untuk menjalankan 
kegiatan bisnis sebagai bentuk membayar value proposition yang dihasilkan. Adapun biaya yang dikeluarkan berbasis area fungsional dibagi menjadi 3 jenis yaitu biaya produksi, biaya pemasaran, biaya administrasi dan umum. Berdasarkan wawancara perusahaan diperoleh bahwa besaran biaya pemasaran, administrasi dan umum ialah 28,8\%. Sedangkan biaya produksi ialah $71,2 \%$. Khusus untuk rincian cost structure dan revenue streams data tersebut merupakan data internal perusahaan sehingga tidak dapat dijelaskan secara mendalam di dalam penelitian ini.

\section{Kekhasan Model Bisnis Jepang di Yukiguni Maitake Co., Ltd.}

Karakter bangsa ialah perilaku atau watak yang mencerminkan masyarakat suatu negara. Karakter bangsa memiliki kaitan yang kuat dengan budaya serta etika suatu bangsa. Menurut Subarkah (2013), karakter-karakter bangsa Jepang secara umum yaitu: bekerja keras, ramah dan sopan, disiplin, jujur, dan inovatif. Yukiguni Maitake Co., Ltd. mampu bertahan lebih dari 35 tahun dan bukanlah waktu yang singkat. Kesuksesan perusahaan tidak terlepas dari karakter bangsa Jepang yang mereka terapkan dalam kehidupan berbisnis, yaitu:

a. Bekerja Keras. Bangsa Jepang terkenal sebagai pekerja keras. Karoushi merupakan istilah yang dikenal bahwa orang Jepang hampir mati karena beratnya melakukan pekerjaan. Berdasarkan data hasil survei International Monetary Fund atau IMF, Jepang berada di posisi ketiga sebagai negara dengan Produk Domestik Bruto (PDB) tertinggi dan menduduki peringkat keempat negara daya beli tinggi di dunia (IMF, 2015). Ini merupakan hasil dari karakter bangsa Jepang yang pekerja keras.

Kerja keras juga diterapkan di Yukiguni Maitake Co., Ltd. Perusahaan yang menggeluti bisnis jamur ini memiliki jumlah karyawan lebih banyak dibagian produksi daripada adminstrasi. Pekerja dibagian produksi harus berdiri sambil mengerjakan pekerjaan. Dalam wawancara dengan kepala produksi, beliau mengatakan bila pekerjaan di pabrik dilakukan dalam posisi duduk, maka pekerjaan akan menjadi lambat dan target tidak terpenuhi. Pekerja harus berdiri 8 hingga 10 jam per hari. Iklim ekstrim dimana musim salju yang berlangsung selama 5 bulan dari November hingga Maret juga menjadi tantangan bagi pekerja.

b. Ramah dan sopan. Bangsa Jepang juga terkenal akan ramah dan sikap sopannya. Mereka sangat menghormati orang yang lebih tua dan lebih tinggi jabatannya. Salah satu kebiasaan mereka ialah memberikan salam hormat 
dengan membungkukkan badan yang disebut dengan ojigi. Bagi karyawan Yukiguni Maitake Co., Ltd. mengucapkan salam kepada sesama pekerja baik kenal maupun tidak merupakan suatu kewajiban. Salah satu kata yang sering diucapkan ialah otsukaresamadeshita yang berarti terimakasih untuk kerja samanya hari ini. Dengan mengucapkan kata tersebut pekerja akan merasa apa yang mereka kerja dihargai oleh orang lain.

c. Disiplin. Displin merupakan salah satu karakter bangsa Jepang yang terkenal. Kedisiplinan bangsa Jepang di segala aspek menjadikan negara Jepang menjadi negara maju yang sukses. Kedisiplinan terlihat dalam budaya kerja di Yukiguni Maitake Co., Ltd. Disiplin waktu menjadi hal yang diutamakan pekerja. Pekerja di perusahaan lebih memilih datang lebih cepat daripada terlambat. Orang yang tidak tepat waktu akan mendapat pandangan negatif dari pekerja lainnya.

d. Jujur. Dalam keseharian bangsa Jepang, kita akan merasakan bagaimana perilaku jujur teraplikasi. Perusahaan akan memberikan yang terbaik kepada konsumen. Salah satu contohnya pada bagian pengemasan jamur. Jamur yang jatuh dari keranjang wajib di buang. Mereka tidak akan memilah bagian yang tidak terkena kotoran, melainkan membuang semua jamur walaupun hal tersebut merugikan perusahaan.

e. Inovatif. Bangsa Jepang selalu melakukan inovasi yang erat kaitannya dengan budaya kaizen. Kaizen merupakan salah satu etos kerja bangsa Jepang yang bertujuan untuk memperbaiki menuju kearah yang lebih baik (Subarkah, 2013). Telah banyak inovasi yang dilakukan perusahaan Yukiguni Maitake Co., Ltd. seperti mampu membudidayakan jamur maitake didalam ruangan yang dimodifikasi sesuai dengan habitat aslinya, menemuka bibit unggul, dan mampu membuat mesin sendiri.

Kelima karakter bisnis diatas sangat erat kaitannya dengan kesuksesan Jepang dalam berbisnis. Jepang juga memiliki model bisnis tersendiri yang tidak lepas dari karakter bangsanya. Model bisnis ini merupakan hal yang khas dan juga terjadi di Yukiguni Maitake Co., Ltd:

a. Konteks budaya. Menurut Edward T. Hall dalam Rogers, dkk (2002), ahli manajemen membagi budaya menjadi dua kategori low context culture dan high-context cultures. Kebanyakan masyarakat barat biasanya diyakini sebagai low context cultures. Ini artinya apa yang dikatakan dan tertulis adalah sumber informasi terpenting antara dua pihak atau lebih. Jepang masuk dalam 
kategori high-context cultures. Ini berarti pesan non-verbal dan situasional menyampaikan makna utama. Mengutarakan perasaan secara langsung dan emosional di depan umum merupakan hal yang kasar sehingga orang Jepang lebih memilih cara lain untuk mengekspresiakan perasaannya. Yukiguni Maitake Co., Ltd melakukan suatu cara agar karyawannya dapat menyampaikan keresahaan yang mereka rasakan dalam bentuk "Tosho Bako" yang berarti kotak konsultasi. Pekerja yang memiliki masalah tetapi tidak bisa secara transparan memaparkan dapat menulis keluh kesah dan memasukan ke dalam kotak tersebut. Ada bagian yang menangani hal tersebut yaitu Person In Charge (PIC) yang akan membantu menyelesaikan masalah secara musyawarah atau kekeluargaan. Bila masalah cukup besar dan tidak terselesaikan, pekerja bisa mendatangkan pengacara dan akan diselesaikan oleh HRD.

b. Tenaga kerja jangka panjang. Banyak yang percaya bahwa cara berpikir orang Jepang tentang pengukuran dari kesuksesaan sangat berbeda dengan orang Barat. Kebudayaan barat biasanya dianggap budaya individualis yang menekankan pada individu, peran, dan prestasi. Sedangkan budaya Jepang adalah budaya koletif, yang mana menekankan pada mencapai tujuan dan prestasi secara bersama (Kreitner, 2007). Karyawan akan mendatangi manajer mereka untuk berkonsultasi mengenai masalah mendalam. Interaksi ini sering terjadi saat mereka keluar untuk minum bersama. (Nathan, 2004). Dapat disimpulkan bahwa karyawan di Jepang lebih memilih menjalin hubungan antar sesama di suatu perusahaan daripada mengejar keuntungan finansial. Karyawan Yukiguni Maitake Co., Ltd juga menerapkan hal tersebut. Berdasarkan hasil wawancara, Banyak karyawan yang sudah mengabdi puluhan tahun. Sesama karyawan sering pergi minum bersama atau pergi ke tempat permandian air panas yang disebut onsen. Kegiatan informal inilah yang membuat mereka menjadi dekat satu sama lain. Hubungan yang deket sesama rekan kerja membuat mereka lebih memilih mengabdi pada satu perusahaan. Yukiguni Maitake Co., Ltd juga memiliki kegiatan informal bernama hiru-orei (昼打礼). Hiru-orei ialah pertemuan yang dilakukan satu bulan sekali diantara jam kerja tepatnya setelah makan siang. Hiru-orei merupakan rapat informal yang biasanya menginformasikan kondisi 
perusahaan, apresiasi pekerja, dan pemberian semangat atau motivasi kepada pekerja dan ucapan terimakasih.
Kegiatan khas Jepang ini dilakukan untuk menjalin hubungan kepercayaan antara manajemen atas dan karyawan.

\begin{tabular}{|c|c|c|c|c|}
\hline \multirow{2}{*}{$\begin{array}{l}\text { Key Partners } \\
\text { - Supplier: Omori } \\
\text { Machinery Co., Ltd; } \\
\text { Midori Anzen Co., } \\
\text { Ltd, Yamato Co., } \\
\text { Ltd.; Chuo Kagaku. } \\
\text { Co., Settsucarton } \\
\text { Co., Ltd.; Fujimari } \\
\text { Kyogu Co., Ltd } \\
\text { Buyer: Rara, Aeon, } \\
\text { Izumi, Yaoko, } \\
\text { Harashin, Ozeki, } \\
\text { raifukoporeshon, } \\
\text { Heiwado. }\end{array}$} & 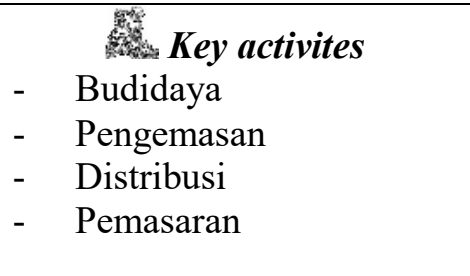 & \multirow{2}{*}{\begin{tabular}{ll} 
& \multicolumn{1}{c}{$\begin{array}{l}\text { Value } \\
\text { Proposition }\end{array}$} \\
- & Kinerja \\
- & Kustomisasi \\
- & Penyelesaian \\
& Pekerjaan \\
- & Design dan \\
& Merek \\
- & Kemudahan \\
& penggunaan \\
- & Pengurangan \\
& resiko
\end{tabular}} & $\begin{array}{l}\text { QCustomer } \\
\text { Relationships } \\
\text { Personal } \\
\text { assistance }\end{array}$ & \multirow{2}{*}{ 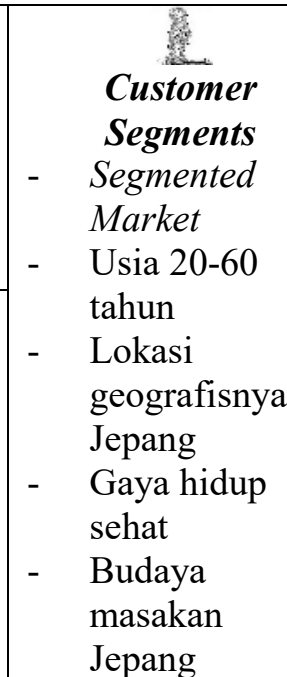 } \\
\hline & 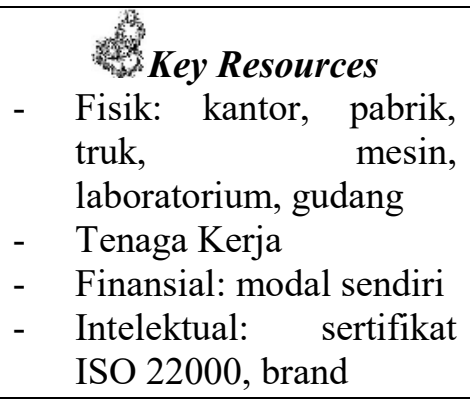 & & $\begin{array}{c}\text { Channels } \\
\text { Direct }=\text { restoran } \\
\text { Indirect }=\text { retailer }\end{array}$ & \\
\hline
\end{tabular}

Gambar 1. Model Bisnis Kanvas Yukiguni Maitake Co., Ltd.

\section{KESIMPULAN DAN SARAN}

\section{Kesimpulan}

Yukiguni Maitake Co., Ltd mampu menjadi perusahaan besar bukan dalam waktu yang singkat. Perusahaan tidak pernah lelah untuk mengembangkan teknologi baru, mencari konsumen, serta menghasilkan produk yang terbaik. Kerja keras, disiplin, jujur, sopan santun, dan inovatif merupakan karaktek khas bangsa Jepang yang teraplikasi didalam kegiatan bisnis perusahaan. Hubungan kekeluargan dan loyalitas antar tenaga kerja yang dibangun dalam kegiatan informal mampu membuat karyawan bertahan dalam satu perusahaan.

\section{Saran}

Yukiguni Maitake Co., Ltd dapat memperluas pasar melalui media publikasi. Salah satu media publikasi yang digunakan Yukiguni Maitake Co., Ltd. ialah web browser yukiguni.maitake.co.jp. Halaman browser tersebut sudah cukup baik dan menarik. Namun, kekurangan media publikasi ini adalah tidak tersedia dalam bahasa asing lain sehingga sulit bagi pasar luar negeri untuk memahami isi halaman browser tersebut. Perusahaan dapat menggunakan seminimalnya berupa bahasa inggris, karena bahasa inggris telah menjadi bahasa internasional yang lebih dikenal masyarakat dunia. 


\section{DAFTAR PUSTAKA}

Amit, Raphael and Christoph Zott. 2010. Creating Value Through Business Model Innovation. MITsloan Management review.

Ashkenazi, M and Jacob, J. 2003. Food Culture In Japan. London: Greenwood Press

Euromonitor International. 2015. Consumtion of Fruits and Vegetables: Global and Asian Perspective. (Diakses 21 Mei 2018)

FAO, 2017. Non-Wood Forest Production in International Statistical System, 2017 , melalui http://www.fao.org diakses pada 3 Agustus 2017

Global Trade Altas (GTA). Top Five Exporters, Importers, and Global Reporting of Fresh or Chilled Mushrooms Other Than Agaricus (HS 070959), 2015. diakses di www.gtis.com Pada 3 Agustus 2017

Mainichi Japan News Daily. 2016. Top Japanese Mushroom Companies Look To Other Asian Markets. (versi online) diakses dilink www.mainichi.jp pada 3 Agustus 2017

Ministry of Agriculture Forestry and Fisheries (MAFF), 2017. Monthly Statistics of Agriculture Forestry and Fisheries.

Melalui http://www.maff.go.jp diakses pada 3 agustus 2017

Nathan, John. 2004. Japan Unbound. Houghton Mifflin Company, Boston New York
Osterwalder, Alexander \& Pigneur, Yves. 2012. Generasi Model Bisnis (Business Model Generation). penerjemah. Jakarta: PT Elex Media Komputindo

Ratna, Patria Maharani. 2015. Bisnis dalam Masyarakat Jepang. Jurnal Izumi Vol 5. No. 1, 2015

Rogers, Everett, dkk. 2002, November 24th Edward T. Hall and The History of Intercultural Communications: The United States and Japan. Keio University, Tokyo.

Setijawibawa, Melina. 2015. Evaluasi Model Bisnis Pada Perusahaan X Menggunakan Business Model Canvas. Agora 3.1: 305-313.

Subarkah, Imam. 2013. Ilham-Ilham Dahsyat dari Kesuksesan Bangsa Jepang. Jakarta: Flash books

Sun, Haiwei. 2013. Competitive Strategies for Chinese Mushroom Export to the Japanese Market. Thesis. Swedish University of Agriculture

Trade Maps, Internasional Trade Center. 2015. Top five exporters, importers, and Global Reporting of Dried Mushrooms Other Than Agaricus (HS 071232/33/390), 2015 diakses di www.intracen.org/marketanalysis Pada 3 Agustus 2017

Yamanaka, Katsuji. 2011. Mushroom Cultivation in Japan. WSMBPM Bulletin 4:1-10. Kyoto Mycological Institute 